\section{The XperCount, a fast and cost-effective method for the enumeration of organisms in environmental media}

\author{
S. Masson, ${ }^{1}$ S. Lavigne, ${ }^{2}$ V. Robitaille, ${ }^{2}$ \\ C. Andrews ${ }^{2}$
}

'Aquarium du Québec, SÉPAQ; ${ }^{1}$ Xpertsea Solutions Inc., Québec, Canada

\section{Introduction}

Aquatic invertebrates and algae are largely used in ecotoxicology studies. Laboratories spend large amounts of resources to maintain, grow and breed organisms. One of the most time-consuming tasks involves quantifying cultures and their feed (e.g. algae and plankton) densities. New and emerging approaches for estimating plankton concentrations have been adopted to overcome the limitations of manual counting, such as coulter counter, optical particle counter, and digital zooplankton image analysis. However, automated systems have some limitations (e.g. volume analysed) and can show higher variability than manual counts. ${ }^{1}$ In some situations estimating the number of organisms in a population still requires manually counting specimens. It has been demonstrated during the last decades, that the accuracy of the estimation density of algae and invertebrates is a function of the sample size, the volume of the concentrated sample, the fraction of the concentrated sample that is counted; it could also be related to samples counted by different people..$^{2-6}$ Counting large volumes $(0.5-1 \mathrm{~L})$ should be ideal to get a good estimation of the plankton density but could require a team of analysts and becomes time-consuming and very expensive. Based on these issues, the field of ecotoxicology could benefit from a mechanized device that quickly and accurately estimates large volume samples. One such instrument is the XperCount (XPC), an optics-based device developed by XpertSea Solutions Inc. in collaboration with leaders in the aquaculture industry and Aquarium du Québec. The XPC can count thousands to millions of small aquatic organisms within a few seconds and can analyze volumes up to $10 \mathrm{~L}$ in a single measurement. The goal of this paper is to present the potential of the XPC for reducing variability in population size estimation of live aquatic cultures.

\section{Materials and Methods}

The XPC technology consists of a sealed optoelectronic unit, installed on the lid of a plastic container, which is adapted and resistant to the marine environment. To perform the count, the lid is removed and a sample of the aquatic culture between 0.5 and $10 \mathrm{~L}$ is poured into the container. The lid is secured back into place and, upon activation an emitter positioned under the lid then sends an electromagnetic (EM) signal towards the bottom of the container. A receptor, located next to the emitter, measures the intensity of the signal that is returned by the organisms. The XPC uses preprogrammed algorithms to correlate the value recorded by the receptor to a concentration or total number of organisms in the container. The final output can be visualized on a simple LED screen and three buttons user interface located on top of the container lid.

Every time measurements are recorded with the XPC, they are stored into a dynamic data bank managed by custom software. Through this software, various statistical analyses and algorithm developments take place, yielding counting applications specific to each type of aquatic organism. This proprietary data bank is one of the key elements of the XPC technology and as it grows, so does the accuracy and overall performance of the system. To facilitate new development integration into the XPC, a data transfer interface serves as a vehicle between the software and hardware components. This interface generates electronic files that can be downloaded on an SD card and inserted into the XPC. This interface allows easy reconfiguration of the platform from a distance, allowing more interaction between the users and XpertSea.

To demonstrate how the XPC can reduce the variability in population size estimation of live aquatic cultures, the small crustacean Artemia salina nauplii $(400 \mu \mathrm{m})$ and with Litopenaeus vannamei shrimps larvae $(7 \mathrm{~mm})$ serve as examples.

Using a micro mesh nylon net $(100 \mathrm{~m}$ porosity), Artemia nauplii were harvested and concentrated into a $1 \mathrm{~L}$ sample, which was then poured into the container of the XPC. After uniformly mixing the organisms, three measurements were performed with the device; then three $10 \mathrm{~mL}$ sub-samples were taken with a LTS $20 \mathrm{~mL}$ micropipette (model L0935053A). Each sub-sample was identified and set aside for manual counting under a binocular using a Ward cell. This operation was repeated 20 times using different dilutions of the Artemia nauplii sample in the XPC container. For each of the 20 dilutions, a volume of Artemia mixture was removed from the container and replaced with clear seawater to keep $1 \mathrm{~L}$ volume constant. Again, three meas-
Correspondence: Stephane Masson, Aquarium du Québec, SÉPAQ, 1675 avenue des Hôtels, Québec, G1W 4S3, Canada.

Tel. +1.418.659.5264 \#251 - Fax +1.418.646-5264.

E-mail: masson.stephane@sepaq.com

Key words: counting organisms, large volumes, easy and quick method.

Conference presentation: part of this paper was presented at the ECOBIM meeting, 2013 May, Montréal, Quebec, Canada.

Acknowledgments: the authors thank Fani Laplante, Moez Khefifi, Svetlana Bahlai and Sandra Le Tourneux from the Aquarium $d u$ Québec as well as Audrey Auclair and LouisSimon Bourgault from XpertSea for their technical assistance to the project. XpertSea would also like to thank the Aquarium du Quebec for providing the facility and resources necessary to this project. A special acknowledgement is also made to the Ministère des Finances et de l'Économie du Québec (MFEQ), to the National Research Council of Canada (NRC) and to Canada Economic Development for Quebec regions (CED) for supporting the founding and growth of XpertSea.

This work is licensed under a Creative Commons Attribution NonCommercial 3.0 License (CC BY-NC 3.0).

\section{(C) Copyright S. Masson et al., 2013}

Licensee PAGEPress, Italy

Journal of Xenobiotics 2013; 3(s1):e10

doi:10.4081/xeno.2013.s1.e10

urements were taken with the XPC and three $10 \mathrm{~mL}$ sub-samples were extracted with the micropipette. Statistical differences between distributions were realized with a Wilcoxon signed ranks test using for non-parametric and paired data. With the shrimp specimens, the impact of sample size on the estimation of a total population was investigated. The larvae were removed from a production tank and concentrated into a 100 liter holding tank. After uniform mixing of the animals, six $25 \mathrm{~mL}$ samples were taken with a spring-operated aliquot. Each $25 \mathrm{~mL}$ sample was manually counted and used to estimate the population in the $100 \mathrm{~L}$ holding tank. The XperCount was then used to count 5, 10 and $15 \mathrm{~L}$ samples from the holding tank. For each volume, six measurements involving new samples were taken (after each measurement the sample was poured back into the holding tank).

\section{Results and Discussion}

By physical principle, the number of Artemia nauplii larvae per $\mathrm{mL}$ should gradually 
decrease with each dilution performed. This can be clearly observed with the XPC measurements but not with the manual counts (Table 1). At the highest densities, the manual counts did not properly reflect the dilutions of the nauplii samples. Although there is no significant difference between distributions (Wilcoxon signed ranks test, $\mathrm{P}=0.688$ ), it can also be observed that the standard deviation is higher for the manual counts than for the XPC measurements at all dilution levels. The same trend can be observed with the shrimp larvae in Table 2. The samples collected using a Stampler pipette yielded higher standard deviation and variation coefficient than the samples counted using the XPC method. These results are not surprising and have been clearly demonstrated by several studies; those indicated that smaller sub-sampled volumes analyzed lead to important errors in count, especially at high organism densities. ${ }^{2,3,7}$

Manual counts showed higher relative standard deviations at lower concentrations with smaller volumes of specimens (Figure 1). For shrimp larvae, the concentration of specimens in the samples remained constant throughout the experiment but the sample sizes differed (5, 10 and 15 L; Table 2). For Artemia nauplii, the sampling volumes remained constant but the concentrations varied by successive dilutions. It is interesting to note that the performance of the XPC did not appear to be affected by the concentration of Artemia specimens in a sample but appeared to be only impacted by the volume of the sample with shrimp larvae. In both cases, the relative standard deviations were higher for manual counts than for the XPC readings. This observation seems to suggest that an optimal ratio can be reached with the XPC based on the sample volume to the size and concentration of specimens. This outcome is especially important for researchers who need accurate results when working with large volumes of live organisms. To date, mathematical models are being used by researchers to determine appropriate rates of sampling for the populations of organisms they are working with. These models have shown benefits of limiting the time spent taking samples but can significantly compromise accuracy when used for larger populations. ${ }^{2}$ The XPC alleviates this compromise between time and accuracy. Using the ability to count larger sample volumes with accuracy and speed, the XPC allows researchers to design and complete reliable experiments within a feasible time frame without sacrificing time or accuracy. The XPC saves time and money and gives users a high level of precision for several types of organisms. Counting applications for several different types of small aquatic organisms have already been developed for the XPC (Table 3).
Table 1. Results for Artemia nauplii counting methods.

\begin{tabular}{lcc} 
Dilution number & $\begin{array}{c}\text { Average of the XPC } \\
\text { measurements } \\
\text { (nauplii per mL) }\end{array}$ & $\begin{array}{c}\text { Average of the } \\
\text { manual counts } \\
\text { (nauplii per mL) }\end{array}$ \\
\hline 1 & $4888(\mathrm{SD}=106)$ & $4267(\mathrm{SD}=1380)$ \\
2 & $4064(\mathrm{SD}=10)$ & $4223(\mathrm{SD}=357)$ \\
\hline 3 & $3692(\mathrm{SD}=34)$ & $4793(\mathrm{SD}=579)$ \\
4 & $3388(\mathrm{SD}=7)$ & $3210(\mathrm{SD}=390)$ \\
\hline 5 & $3052(\mathrm{SD}=10)$ & $2140(\mathrm{SD}=322)$ \\
6 & $2653(\mathrm{SD}=50)$ & $1317(\mathrm{SD}=163)$ \\
\hline 7 & $2116(\mathrm{SD}=26)$ & $2400(\mathrm{SD}=0)$ \\
\hline 8 & $2028(\mathrm{SD}=15)$ & $1510(\mathrm{SD}=70)$ \\
\hline 9 & $1538(\mathrm{SD}=5)$ & $1340(\mathrm{SD}=348)$ \\
\hline 11 & $1144(\mathrm{SD}=8)$ & $1233(\mathrm{SD}=321)$ \\
12 & $1082(\mathrm{SD}=18)$ & $1283(\mathrm{SD}=29)$ \\
\hline 13 & $713(\mathrm{SD}=4)$ & $927(\mathrm{SD}=263)$ \\
14 & $643(\mathrm{SD}=12)$ & $467(\mathrm{SD}=58)$ \\
\hline 15 & $512(\mathrm{SD}=5)$ & $933(\mathrm{SD}=404)$ \\
16 & $433(\mathrm{SD}=2)$ & $747(\mathrm{SD}=323)$ \\
\hline 17 & $379(\mathrm{SD}=9)$ & $293(\mathrm{SD}=76)$ \\
\hline 18 & $307(\mathrm{SD}=6)$ & $373(\mathrm{SD}=162)$ \\
\hline 20 & $305(\mathrm{SD}=1)$ & $110(\mathrm{SD}=20)$ \\
\hline & $236(\mathrm{SD}=10)$ & $187(\mathrm{SD}=81)$ \\
\hline $0(\mathrm{SD}=0)$ & \\
\hline
\end{tabular}

XPC, XperCount; SD, standard deviation.

Table 2. Results for estimating a shrimp larvae population using different volume subsamples.

\begin{tabular}{lcc} 
Sampling method & Sampled volume & Volumetric total population estimation \\
Stampler pipette & $25 \mathrm{~mL}$ & $1,391,200(\mathrm{SD}=105,239) \mathrm{CV}=7.56 \%$ \\
XperCount & $5 \mathrm{~L}$ & $1,244,194(\mathrm{SD}=67,570) \mathrm{CV}=5.73 \%$ \\
XperCount & $10 \mathrm{~L}$ & $1,251,725 \mathrm{SD}=47,198) \mathrm{CV}=3.77 \%$ \\
XperCount & $15 \mathrm{~L}$ & $1,254,010(\mathrm{SD}=29,718) \mathrm{CV}=2.37 \%$ \\
\hline
\end{tabular}

SD, standard deviation; CV, confidence interval?

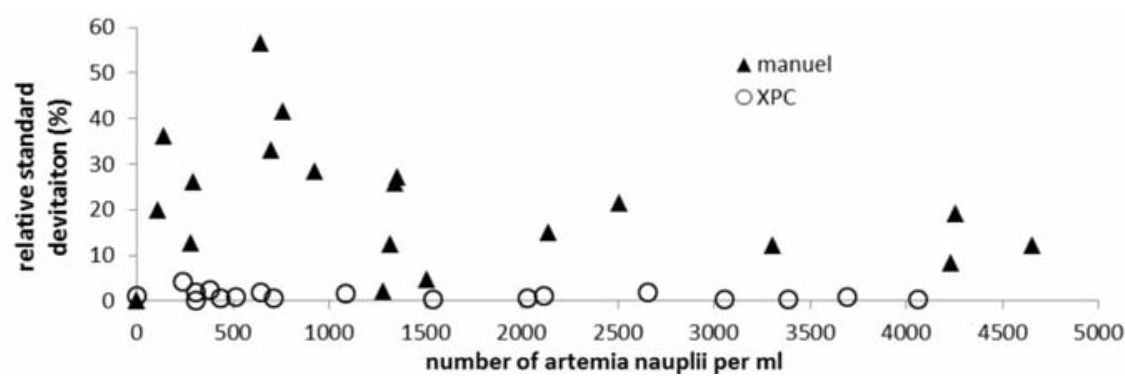

Figure 1. Illustration of the relative standard deviation for both counting estimation methods as a function of the concentration of Artemia nauplii per $\mathrm{mL}$. 
Table 3. Different counting applications developed for the XperCount.

\begin{tabular}{|c|c|c|c|}
\hline Type of specimen & Stage & Size & Max. concentration \\
\hline \multicolumn{4}{|l|}{ Shrimp } \\
\hline Penaeus vannamei, monodon, stylirostris, indicus, etc. & $\begin{array}{l}\text { Eggs } \\
\text { Nauplii } \\
\text { Larvae } \\
\text { Juvenile }\end{array}$ & $\begin{array}{c}300-400 \mu \mathrm{m} \\
400-600 \mu \mathrm{m} \\
3-12 \mathrm{~mm} \\
12-20 \mathrm{~mm}\end{array}$ & $\begin{array}{c}2,000,000-1,000,000 / \mathrm{L} \\
600,000-300,000 / \mathrm{L} \\
40,000-7500 / \mathrm{L} \\
7500-500 / \mathrm{L}\end{array}$ \\
\hline $\begin{array}{l}\text { Fish } \\
\text { Sea bream, Barramundi, Zebra fish, Brook and Rainbow trout, etc. }\end{array}$ & $\begin{array}{l}\text { Eggs } \\
\text { Larvae } \\
\text { Fingerling }\end{array}$ & $\begin{array}{c}1-6 \mathrm{~mm} \\
2-15 \mathrm{~mm} \\
15-45 \mathrm{~mm}\end{array}$ & $\begin{array}{c}500,000-20,000 / \mathrm{L} \\
50,000-5000 / \mathrm{L} \\
1,000-200 / \mathrm{L}\end{array}$ \\
\hline $\begin{array}{l}\text { Shellfish } \\
\text { Mussel, Abalone, American lobster, etc. }\end{array}$ & $\begin{array}{l}\text { Eggs } \\
\text { Larvae } \\
\text { Spat } \\
\text { Juvenile }\end{array}$ & $\begin{array}{c}40-90 \mu \mathrm{m} \\
100-200 \mu \mathrm{m} \\
250-400 \mu \mathrm{m} \\
500-4000 \mu \mathrm{m}\end{array}$ & $\begin{array}{c}10,000,000-5,000,000 / \mathrm{L} \\
5,000,000-3,000,000 / \mathrm{L} \\
250,000-100,000 / \mathrm{L} \\
100,000-10,000 / \mathrm{L}\end{array}$ \\
\hline $\begin{array}{l}\text { Microalgae } \\
\text { Chaetoceros, Thalassiosira, Pavlova, Isochrysis, etc. }\end{array}$ & & $1-30 \mu \mathrm{m}$ & $100,000,000-6,000,000 / \mathrm{mL}$ \\
\hline $\begin{array}{l}\text { Rotifers } \\
\text { Artemia salina }\end{array}$ & Nauplii & $\begin{array}{l}100-500 \mu \mathrm{m} \\
\sim 400 \mu \mathrm{m}\end{array}$ & $\begin{array}{l}30,000-10,000 / \mathrm{mL} \\
\quad 6000 / \mathrm{mL}\end{array}$ \\
\hline
\end{tabular}

\section{Conclusions}

The coherence between the dilutions and XPC measurements, as well as the low coefficients of variation throughout the counts for both experiments, supports the hypothesis that performing counts on larger volumes can reduce the variability in population size estimation of live cultures, especially at lower concentrations. To confirm these results further, similar work is actually being conducted to validate the accuracy and the repeatability of the XPC system with Artemia and other organisms (e.g. algae, rotifers, mysis and fish larvae). Limitations of the XPC are also being investigated. Foreign particulates such as feed residuals, hydra and other contaminations and molts could potentially interfere with the EM signals emitted by the technology platform and have to be included into the product development strategy. Researchers can use the XPC to determine quickly and accurately the densities of algae, invertebrates and fish cultures at different growth stages. Also, the possibility of doing experiments directly in the container (such as toxicant additions) will enable unprecedented time series analysis and studies. So far in terms of better resource management, the XPC has demonstrated the potential to become an indispensable tool for aquatic ecotoxicology studies.

\section{References}

1. Embleton KV, Gibson CE, Heaney SI. Automated counting of phytoplankton by pattern recognition: a comparison with a manual counting method. J Plankt Res 2003;25:669-81.

2. Alden III RW, Dahiya RC, Young Jr RJ. A method for the enumeration of zooplank- ton subsamples. J Exp Mar Biol Ecol 1982; 59:185-206.

3. Frontier S. Calcul de l'erreur de comptage de zooplancton. J Exp Mar Biol Ecol 1972;8: 121-32.

4. Guelpen LV, Markle DF, Duggan DJ. An evaluation of accuracy, precision, and speed of several zooplankton subsampling techniques. J Cons Int Explor Mer 1982;40: 226-36.

5. Rott E. Some results from phytoplankton counting intercalibrations. Schweiz Z Hydrol 1981;43:34-62.

6. Willén E. A simplified method of phytoplankton counting. Brit Phycol J 1976; 11: 265-78.

7. Hardin MP, Hutchins DL, Chamberlain GW, Aldrich DV. The problem of estimating postlarval shrimp populations: temperature and size effect on accuracy. Texas Agr Exp Stat Proj Aquac Eng 1985;4:85-92. 